\title{
Identification of an Optimal Population for Allogeneic Hematopoietic Stem Cell Transplantation in Patients With Mature T and NK Cell Neoplasms
}

\author{
EUN HEE JUNG ${ }^{1}$, DONG-YEOP SHIN ${ }^{1,2,3}$, JUNSHIK HONG ${ }^{1,2,3}$, INHO KIM ${ }^{1}$, \\ SUNG-SOO YOON ${ }^{1,2,3}$, YOUNGIL $\mathrm{KOH}^{1,2,3}$ and JA MIN BYUN ${ }^{1,2,3}$ \\ ${ }^{1}$ Department of Internal Medicine, Seoul National University College of Medicine, \\ Seoul National University Hospital, Seoul, Republic of Korea; \\ ${ }^{2}$ Cancer Research Institute, Seoul National University Hospital, Seoul, Republic of Korea; \\ ${ }^{3}$ Center for Medical Innovation, Biomedical Research Institute, \\ Seoul National University Hospital, Seoul, Republic of Korea
}

\begin{abstract}
Background/Aim: The prognosis of mature T and natural killer (NK) cell neoplasms still remains dismal, despite the advancements in the understanding of the heterogeneous features of these diseases. As allogeneic stem cell transplantation (alloSCT) is an attractive salvage option for relapsed/refractory patients, we conducted this study to identify those who might benefit the most from alloSCT. Patients and Methods: This was a retrospective, single-center, longitudinal cohort study of patients who received alloSCT between December 2019 and January 2000. Results: The median relapse-free survival and overall survival were 4.4 and 10.0 months, respectively. Disease control status at alloSCT and number of previous treatments were associated with survival outcomes. The conditioning intensity did not significantly alter survival. Conclusion: AlloSCT offers a cure chance for selected relapsed or refractory $T$ and $N K$ cell neoplasms, especially when used early and the disease is well controlled prior to transplantation.
\end{abstract}

Mature T and natural killer (NK) cell neoplasms consist of a wide spectrum of lymphoproliferative disorders with varying geographic distributions and clinical courses. With increasing knowledge about their immunophenotypic and

This article is freely accessible online.

Correspondence to: Ja Min Byun, MD, Ph.D., Department of Internal Medicine, Seoul National University Hospital, 101, Daehak-ro, Jongro-gu, Seoul 03080, Republic of Korea. Tel: +82 220721477, Fax: +82 27629662, e-mail jaminbyun@naver.com

Key Words: Allogeneic hematopoietic stem cell transplantation, lymphoma, T-cell lymphoma. molecular characteristics, these lymphomas have repeatedly been classified (1). Unfortunately, better understanding of this disease has not been accompanied by therapeutic improvements. Cyclophosphamide (Cy)- and anthracyclinebased treatment remains the first line therapy in most cases, and even with the introduction of etoposide and 1asparaginase and the incorporation of consolidation autologous stem cell transplantation (autoSCT), the progression-free survival rate at 2 years lingers at $42 \%$ (2, $3)$. Thus, effective treatment strategies to prevent relapse and allow salvage are needed.

Several studies have suggested allogeneic stem cell transplantation (alloSCT) as an option for long-term disease control based on its graft-versus-lymphoma (GVL) effects (4-6). Unfortunately, it is still difficult to define when and who should undergo alloSCT because the outcomes are still unsatisfactory, including high rates of treatment related mortality (TRM). The success of alloSCT with reduced intensity conditioning (RIC) has mitigated some of the concern $(6,7)$, but questions remain including identification of the optimal population and transplant timing. In this regard, we performed a detailed analysis of Korean patients with mature $\mathrm{T}$ and NK cell neoplasms undergoing alloSCT. In particular, we focused on the feasibility of and prognostic factors associated with alloSCT in real-life clinical practice.

\section{Patients and Methods}

Study design and subjects. This was a retrospective, longitudinal cohort study of patients with mature T and NK cell neoplasms aged older than 18 years who received alloSCT at Seoul National University Hospital between January 2000 and December 2019. The diagnosis and classification of mature $\mathrm{T}$ and NK cell neoplasms were performed according to the World Health Organization criteria at the time of diagnosis $(1,8,9)$. Initially, 45 patients with mature 


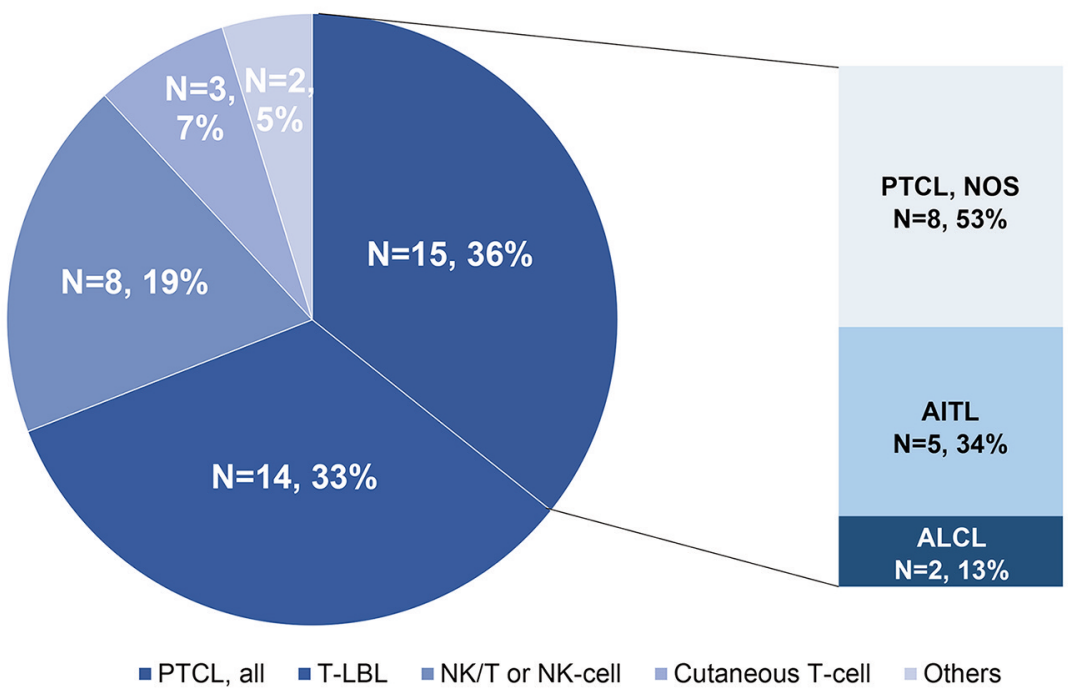

Figure 1. Subtype of lymphoma. PTCL: Peripheral T-cell lymphoma; TLBL: T lymphoblastic lymphoma; AITL: angioimmunoblastic T-cell lymphoma; ALCL: anaplastic large cell lymphoma.

$\mathrm{T}$ and NK neoplasms undergoing alloSCT at any point during their clinical course, whether it was frontline or salvage consolidation, were screened. After eliminating 1 patient who was HIV-positive, 1 with an uncertain diagnosis, and 1 with acute lymphoblastic leukemia, a total of 42 patients were deemed eligible. Among these final 42 patients, $15(35.7 \%)$ had peripheral T-cell lymphoma (PTCL), 14 (33.3\%) had T lymphoblastic lymphoma (T-LBL), 8 (19.0\%) had NK/T cell lymphoma, 3 (7.1\%) had cutaneous T cell lymphoma, and $2(4.8 \%)$ had T-cell prolymphocytic leukemia (TPLL) (Figure 1). Their medical records were reviewed and analyzed for demographics, baseline disease characteristics, chemotherapy, factors related to alloSCT, response to alloSCT, adverse events, and survival outcomes.

Definitions. Responses to therapy and disease status were defined according to current conventional standard criteria $(10,11)$. Conditioning regimen intensity was classified according to consensus criteria (12). Acute graft-versus-host disease (GVHD) grading was performed according to the standard criteria (13). Chronic GVHD was classified as mild, moderate, or severe according to the 2014 National Institutes of Health consensus criteria (14). TRM was defined as death without progression of underlying lymphoma. Relapse free survival (RFS) was defined as the time from stem cell infusion to relapse or death from any cause. Overall survival (OS) was defined as the time from stem cell infusion to death of any cause. Neutrophil engraftment was defined as an absolute neutrophil count (ANC) $>0.5 \times 10^{9} / 1$ on 3 consecutive measurements. Platelet recovery was defined as 7 consecutive measurements of $20.0 \times 10^{9} / 1$ without transfusion.

Statistical analysis. Differences between groups were assessed using Student's $t$-test or one-way analysis of variance for continuous variables, and Pearson's chi-square test for categorical variables, as indicated. The RFS and OS curves were estimated using the Kaplan-Meier method. If patients survived without death or progression, survival was censored at the latest date of follow- up when no death or progression was confirmed. Cumulative incidence curves were used in a competing-risk setting to calculate the probability of acute and chronic GVHD and TRM. For GVHD, death without an event was considered the competing event. For TRM, relapse was considered the competing event. Associations between potential prognostic factors and survival outcomes were evaluated using Cox's proportional hazard regression models. A stepwise backward procedure was used, and all predictors achieving a $p$-value below 0.05 were considered and sequentially removed if the $p$-value in the multivariate model was above 0.05 . All data were analyzed using the Statistical Package for the Social Sciences software (SPSS ${ }^{\circledR}$ Statistics, version 22.0 , IBM ${ }^{\circledR}$, New York, NY, USA). Statistical significance was considered at $p$ values $<0.05$.

\section{Results}

Patient characteristics. Baseline patient characteristics are summarized in Table I. The median age at diagnosis of all patients was 35.0 years (range $=17-62$ years). The majority of the patients (90.5\%) had Ann Arbor stage III-IV disease with bone marrow involvement. The median number of previous lines of therapy before alloSCT was 4 (range $=1-8)$, counting prior autoSCT as one regimen. There were 18 patients $(42.9 \%)$ who underwent autoSCT. The median time from diagnosis to alloSCT was 16.0 months (range=2-71 months). At the time of transplantation, 17 patients $(40.5 \%)$ were in the first or subsequent complete response (CR); 9 were in CR1 and 8 were in CR2. There were 12 (28.6\%) patients with uncontrolled disease [i.e. progressive disease (PD)] at the time of alloSCT. With respect to the donor source, most patients $(38 / 42,90.5 \%)$ had matched donors. Regarding the conditioning regimen, a similar number of 
Table I. Baseline characteristics of all patients.

\begin{tabular}{|c|c|}
\hline Characteristics & $\mathrm{N}$ \\
\hline Age at alloSCT, years* (median, range) & $35.0(17-62)$ \\
\hline Gender, male & $33(71.7 \%)$ \\
\hline \multicolumn{2}{|l|}{ Lymphoma subtypes } \\
\hline Peripheral T-cell lymphoma & $15(35.7 \%)$ \\
\hline T lymphoblastic lymphoma & $14(33.3 \%)$ \\
\hline NK/T cell lymphoma & $8(19.0 \%)$ \\
\hline Cutaneous $\mathrm{T}$ cell lymphoma & $3(7.1 \%)$ \\
\hline T-cell prolymphocytic leukemia & $2(4.8 \%)$ \\
\hline \multicolumn{2}{|l|}{ PIT score } \\
\hline 0 & $6(14.3 \%)$ \\
\hline 1 & $15(35.7 \%)$ \\
\hline 2 & $19(45.2 \%)$ \\
\hline Extranodal involvement $(>1)$ & $38(90.5 \%)$ \\
\hline Previous lines of treatment before alloSCT & $4(1-8)^{*}$ \\
\hline 1 & $3(7.1 \%)$ \\
\hline 2 & $9(21.4 \%)$ \\
\hline 3 & $9(21.4 \%)$ \\
\hline$\geq 4$ & $21(50.0 \%)$ \\
\hline Previous autoSCT & $18(42.9 \%)$ \\
\hline Time from diagnosis to alloSCT, months* & $16.0(2-71)$ \\
\hline Time from last chemo to alloSCT, months* & $1.9(0.5-13.4)$ \\
\hline \multicolumn{2}{|l|}{ Year of alloSCT } \\
\hline $2000-2004$ & $3(7.1 \%)$ \\
\hline 2005-2009 & $11(26.2 \%)$ \\
\hline $2010-2014$ & $6(14.3 \%)$ \\
\hline 2015-2019 & $22(52.4 \%)$ \\
\hline \multicolumn{2}{|l|}{ Disease status at transplantation } \\
\hline $\mathrm{CR}$ & $17(40.5 \%)$ \\
\hline PR & $13(31.0 \%)$ \\
\hline Others & $12(28.5 \%)$ \\
\hline \multicolumn{2}{|l|}{ Conditioning regimen } \\
\hline MAC & $23(54.8 \%)$ \\
\hline $\mathrm{BuCy} / \mathrm{BuFlu} / \mathrm{TBI}-$ based/others & $\begin{array}{c}14(33.3 \%) / 5(11.9 \%) \\
3(7.1 \%) / 1(2.4 \%)\end{array}$ \\
\hline RIC & $19(45.2 \%)$ \\
\hline BuFlu/others & $\begin{array}{c}16(38.1 \%) / \\
3(7.1 \%)\end{array}$ \\
\hline \multicolumn{2}{|l|}{ Donor source } \\
\hline Matched related donor & $27(64.3 \%)$ \\
\hline Matched unrelated donor & $11(26.2 \%)$ \\
\hline Haplo-identical & $4(9.5 \%)$ \\
\hline \multicolumn{2}{|l|}{ Sex matching } \\
\hline Female donor to male recipient & $7(16.7 \%)$ \\
\hline \multicolumn{2}{|l|}{ Modified EBMT risk score } \\
\hline $1-3$ & $21(50.0 \%)$ \\
\hline $4-6$ & $21(50.0 \%)$ \\
\hline Infused CD $34, \times 106 / \mathrm{kg}^{*}$ & $4.93(1.26-14.34)$ \\
\hline \multicolumn{2}{|l|}{ GVHD prophylaxis } \\
\hline Cyclosporine based & $34(70.9 \%)$ \\
\hline Tacrolimus based & $8(19.1 \%)$ \\
\hline ATG use & $21(50 \%)$ \\
\hline
\end{tabular}

AlloSCT: Allogeneic stem cell transplantation; PIT: prognostic index for T-cell lymphoma; CR: complete remission; PR: partial remission; MAC: myeloablative conditioning; RIC: reduced intensity conditioning; $\mathrm{Bu}$ : busulfan; Cy: cyclophosphamide; Flu: fludarabine; TBI: total body irradiation; EBMT: European Blood and Marrow Transplantation; CD34: cluster of differentiation; GVHD: graft-versus-host disease; ATG: anti-thymoglobulin. *Represents median (range).
Table II. Transplantation outcomes.

\begin{tabular}{lc}
\hline Parameters & $\mathrm{N}$ \\
\hline Follow-up from diagnosis, months (median, range) & $33(4-175)$ \\
Neutrophil engraftment & $37(88.1 \%)$ \\
Time to neutrophil engraftment, days (median, range) & $14(8-24)$ \\
Platelet recovery & $34(81.0 \%)$ \\
Time to platelet recovery, days (median, range) & $13(7-47)$ \\
Cumulative incidence of any acute GVHD at Day 100 & \\
Grade II-IV acute GVHD & $31.6 \%$ \\
Cumulative incidence of any chronic GVHD at 1 year & \\
Moderate-severe chronic GVHD & $28.7 \%$ \\
Relapse after alloSCT & $27(64.3 \%)$ \\
Further treatment after alloSCT & $14(33.3 \%)$ \\
$\quad$ CTx only & $11(26.2 \%)$ \\
CTx followed by 2nd alloSCT & $2(4.8 \%)$ \\
RTx only & $1(2.4 \%)$ \\
Treatment related mortality at 1 year & $9(21.4 \%)$ \\
GVHD & $2(4.8 \%)$ \\
Infection & $6(14.3 \%)$ \\
VOD & $1(2.4 \%)$ \\
\hline
\end{tabular}

AlloSCT: Allogeneic stem cell transplantation; GVHD: graft-versus-host disease; CTx: chemotherapy; RTx: radiotherapy; VOD: veno-occlusive disease.

patients underwent myeloablative conditioning (MAC) (23/42, 54.8\%) and RIC (19/42, 45.2\%).

Engraftment and chimerism. As shown in Table II, neutrophil engraftment was observed in $37(88.1 \%)$ patients and platelet engraftment was observed in $34(81.0 \%)$ patients. The median time to neutrophil and platelet engraftment was 14 days (range $=8-24$ days) and 13 days (range $=7-47$ days) respectively. Chimerism at 1 month was available for 31 patients: $21(67.7 \%)$ showed complete chimerism, while 10 patients showed mixed chimerism. Among 23 patients undergoing RIC, 11 patients $(47.8 \%)$ achieved complete chimerism at 1 month.

Complications of alloSCT. The cumulative incidence of grade II-IV acute GVHD at day 100 was $31.6 \%$, and the cumulative incidence of moderate to severe chronic GVHD at 1 year was $28.7 \%$ (Table II). There was no difference in the occurrence of acute GVHD according to the conditioning regimen, including 7 patients who underwent RIC (30.4\%) and 6 patients who underwent MAC (31.5\%). The occurrence of chronic GVHD between the two groups (RIC, $17.4 \%$ vs. MAC, $21.1 \%$ ) was also similar.

The TRM at 1 year was $21.4 \%$. The main causes of death were as follows: infection in 6 patients (14.3\%), GVHD in 2 patients $(4.8 \%)$ and venous-occlusive disease in 1 patient $(2.4 \%)$. According to the conditioning intensity, the TRM at 1 year was $26.1 \%$ for patients undergoing MAC compared to $10.5 \%$ for patients undergoing RIC. 

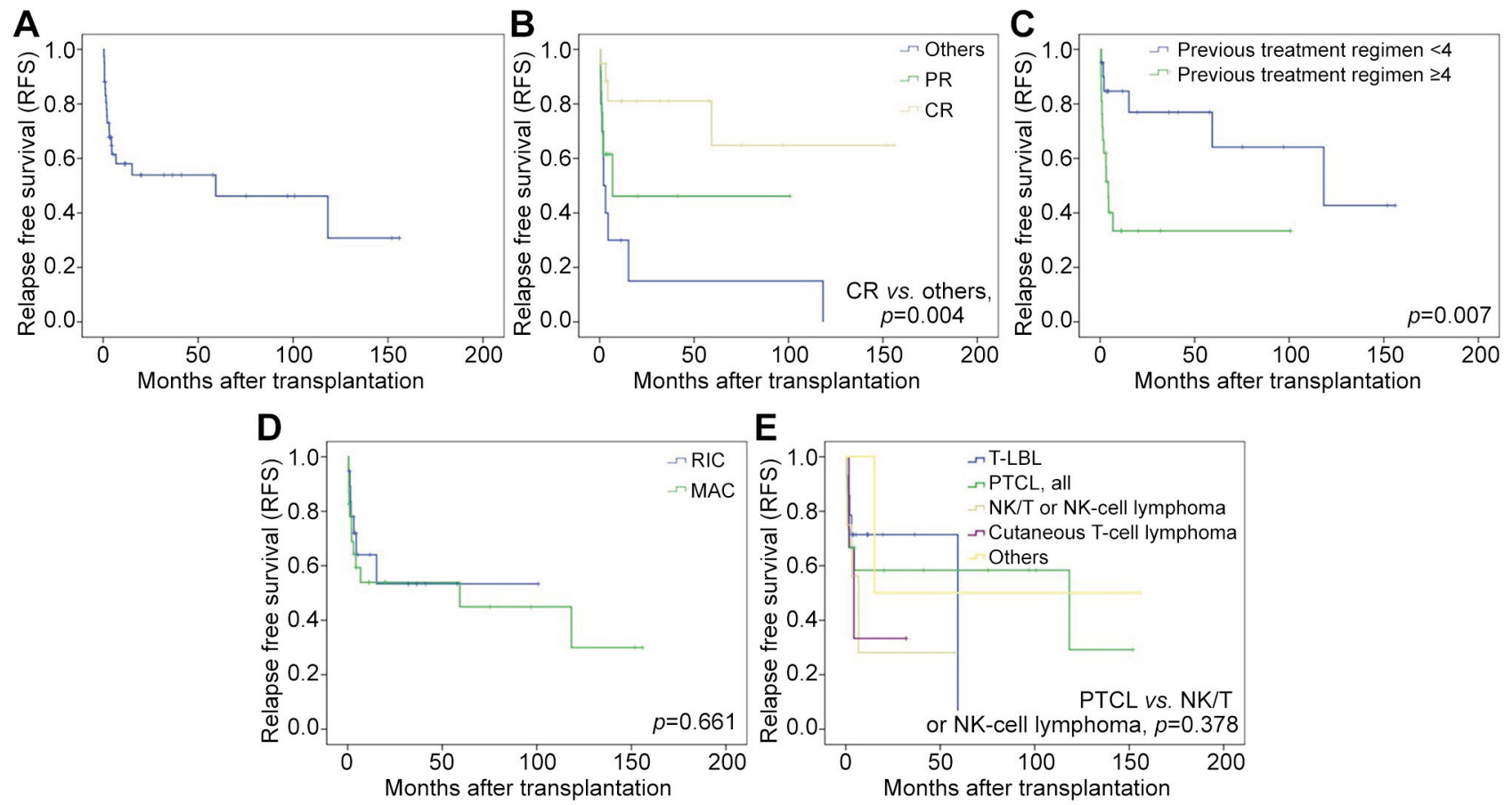

Figure 2. Kaplan-Meier curves of relapse-free survival. (A) All patients; (B) Disease status at allogenic stem cell transplantation; (C) No. of previous treatment regimens, $<4$ vs. $\geq 4 ;(D)$ Conditioning regimen, reduced intensity conditioning (RIC) vs. myeloablative conditioning (MAC); (E) Subtype of lymphoma. CR: Complete response; PR: partial response; PTCL: peripheral T-cell lymphoma; TLBL: T lymphoblastic lymphoma.
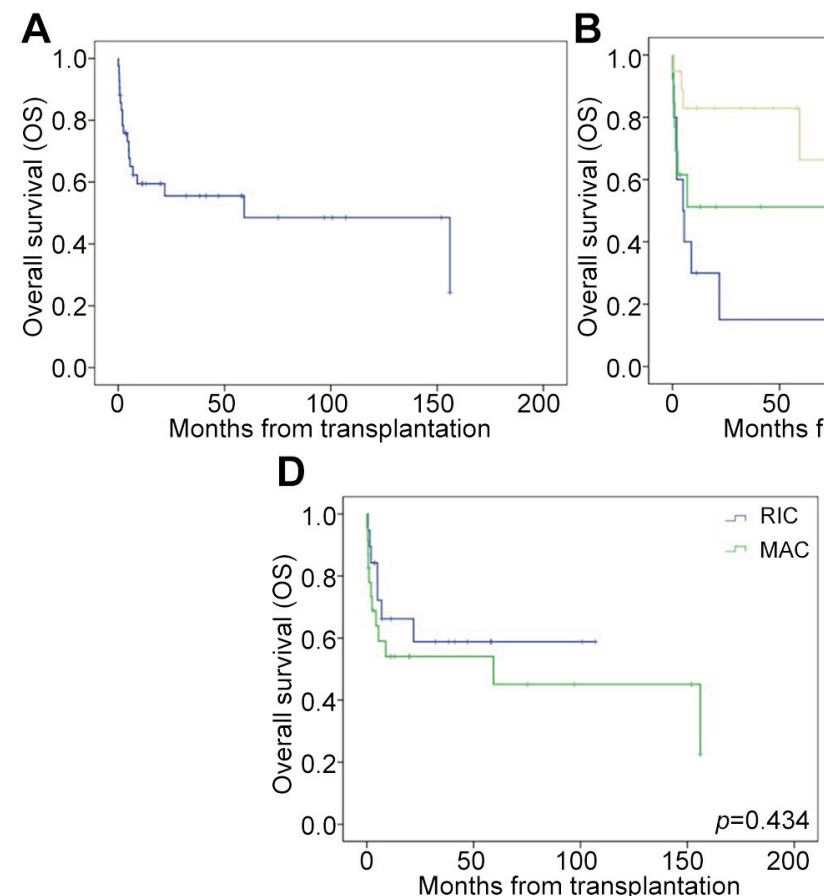

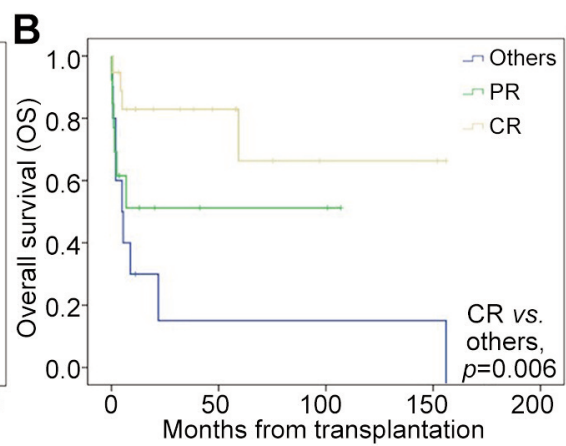

E

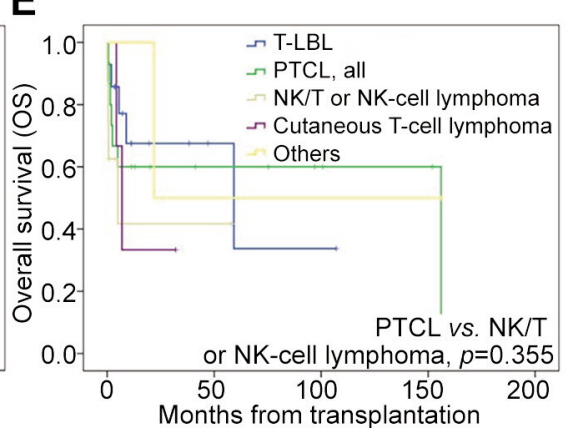

Figure 3. Kaplan-Meier curves of overall survival. (A) All patients; (B) Disease status at allogenic stem cell transplantation (alloSCT); (C) No. of previous treatment regimens, $<4$ vs. $\geq 4 ;$ (D) Conditioning regimen, RIC vs. MAC; (E) Subtype of lymphoma. PTCL: Peripheral T-cell lymphoma; CR: complete response; PR: partial response; TLBL: T lymphoblastic lymphoma; MAC: myeloablative conditioning; RIC: reduced intensity conditioning. 
Table III. Risk factors for transplantation outcomes on multivariate analyses.

\begin{tabular}{|c|c|c|}
\hline & HR $(95 \% \mathrm{CI})$ & $p$-Value \\
\hline \multicolumn{3}{|l|}{ Relapse Free Survival } \\
\hline No. previous treatment regimen, $<4$ vs. $\geq 4$ & $3.340(0.963-11.592)$ & 0.057 \\
\hline Disease status at alloSCT & & 0.057 \\
\hline $\mathrm{SD}+\mathrm{PD}$ & 1.000 & \\
\hline $\mathrm{PR}$ & $0.400(0.106-1.515)$ & 0.177 \\
\hline $\mathrm{CR}$ & $0.116(0.019-0.695)$ & 0.018 \\
\hline Modified EBMT score, 1-3 vs. 4-6 & $2.042(0.526-7.921)$ & 0.302 \\
\hline Subtype of lymphoma & & 0.306 \\
\hline T-lymphoblastic lymphoma & 1.000 & \\
\hline Peripheral T-cell lymphoma, NOS & $1.121(0.294-4.275)$ & 0.868 \\
\hline NK/T cell lymphoma & $5.186(0.877-30.669)$ & 0.070 \\
\hline Cutaneous T cell lymphoma & $3.877(0.538-27.938)$ & 0.179 \\
\hline T-cell prolymphocytic leukemia & $1.502(0.128-17.564)$ & 0.746 \\
\hline \multicolumn{3}{|l|}{ Conditioning regimen, RIC $v s$. MAC } \\
\hline RIC & 1.000 & \\
\hline MAC & $1.340(0.442-4.058)$ & 0.605 \\
\hline \multicolumn{3}{|l|}{ Overall Survival } \\
\hline No. previous treatment regimen, $<4$ vs. $\geq 4$ & $5.779(1.547-21.591)$ & 0.009 \\
\hline Disease status at alloSCT & & 0.033 \\
\hline $\mathrm{SD}+\mathrm{PD}$ & 1.000 & \\
\hline $\mathrm{PR}$ & $0.490(0.128-1.873)$ & 0.297 \\
\hline $\mathrm{CR}$ & $0.090(0.015-0.546)$ & 0.009 \\
\hline Modified EBMT score, 1-3 vs. 4-6 & $1.633(0.479-5.564)$ & 0.433 \\
\hline Subtype of lymphoma & & 0.038 \\
\hline T-lymphoblastic lymphoma & 1.000 & \\
\hline Peripheral T-cell lymphoma, NOS & $1.553(0.399-6.047)$ & 0.526 \\
\hline NK/T cell lymphoma & $17.444(2.577-118.094)$ & 0.003 \\
\hline Cutaneous T cell lymphoma & $5.193(0.699-38.601)$ & 0.107 \\
\hline T-cell prolymphocytic leukemia & $3.747(0.291-48.310)$ & 0.311 \\
\hline \multicolumn{3}{|l|}{ Conditioning regimen, RIC vs. MAC } \\
\hline RIC & 1.000 & \\
\hline MAC & $2.512(0.767-8.227)$ & 0.128 \\
\hline
\end{tabular}

AlloSCT: Allogeneic stem cell transplantation; EBMT: European Blood and Marrow Transplantation; RIC: reduced intensity conditioning; MAC: myeloablative conditioning; CR: complete remission; PR: partial remission; SD: stable disease; PD: progressive disease; NOS: not otherwise specified.

Twenty-seven patients $(64.3 \%)$ relapsed after alloSCT and $14(33.3 \%)$ were able to receive intensive treatment after relapse. All but 1 patients received cisplatin based chemotherapy, either gemcitabine-dexamethasone-cisplatin or dexamethasone-cytarabine-cisplatin, and 2 were able to undergo second alloSCT.

Survival outcomes. The median follow-up duration from diagnosis was 33.0 months (range $=4-175$ months). The median RFS was 4.4 months (range $=0.39-156.04$ months) and the median OS was 10.0 months (range $=0.39-156.04$ months) for all patients. RFS curves for all patients are shown in Figure 2. The followings were associated with RFS: disease status at the time of alloSCT (Figure 2B; CR, 11.18 months; PR, 3.61 months; others 3.80 months; CR vs. others, $p=0.004$; CR vs. PR, $p=0.099$; PR vs. others, $p=0.525$ ) and number of previous treatment (Figure $2 \mathrm{C} ;<4$ lines, 15.21 months $v s . \geq 4$ lines, 3.21 months, $p=0.007)$. Multivariate analysis identified CR state at alloSCT as the sole prognostic factor (Table III). There were no differences in RFS with regards to conditioning intensity (RIC, 4.25 months vs. MAC, 4.46 months, $p=0.661)$.

The OS curves are shown in Figure 3. The disease status at alloSCT (Figure 3B; CR, 19.68 months; PR, 3.64 months; others 7.20 months; CR vs. others, $p=0.006$; CR vs. PR, $p=0.071$, PR vs. others, $p=0.542)$ and number of previous treatment (Figure 3C; $<4$ lines, 38.29 months vs. $\geq 4$ lines, 4.29 months, $p=0.004$ ) were associated with OS. In addition, longer OS was observed in patients who underwent RIC compared to those who underwent MAC (Figure 3D; RIC, 11.29 months $v s$. MAC, 8.89 months, $p=0.434)$. Analyzing the differences between lymphoma subtypes, the longest median OS of 16.34 months was noted in the PTCL group (Figure 3E). In multivariate analysis (Table III), more than 


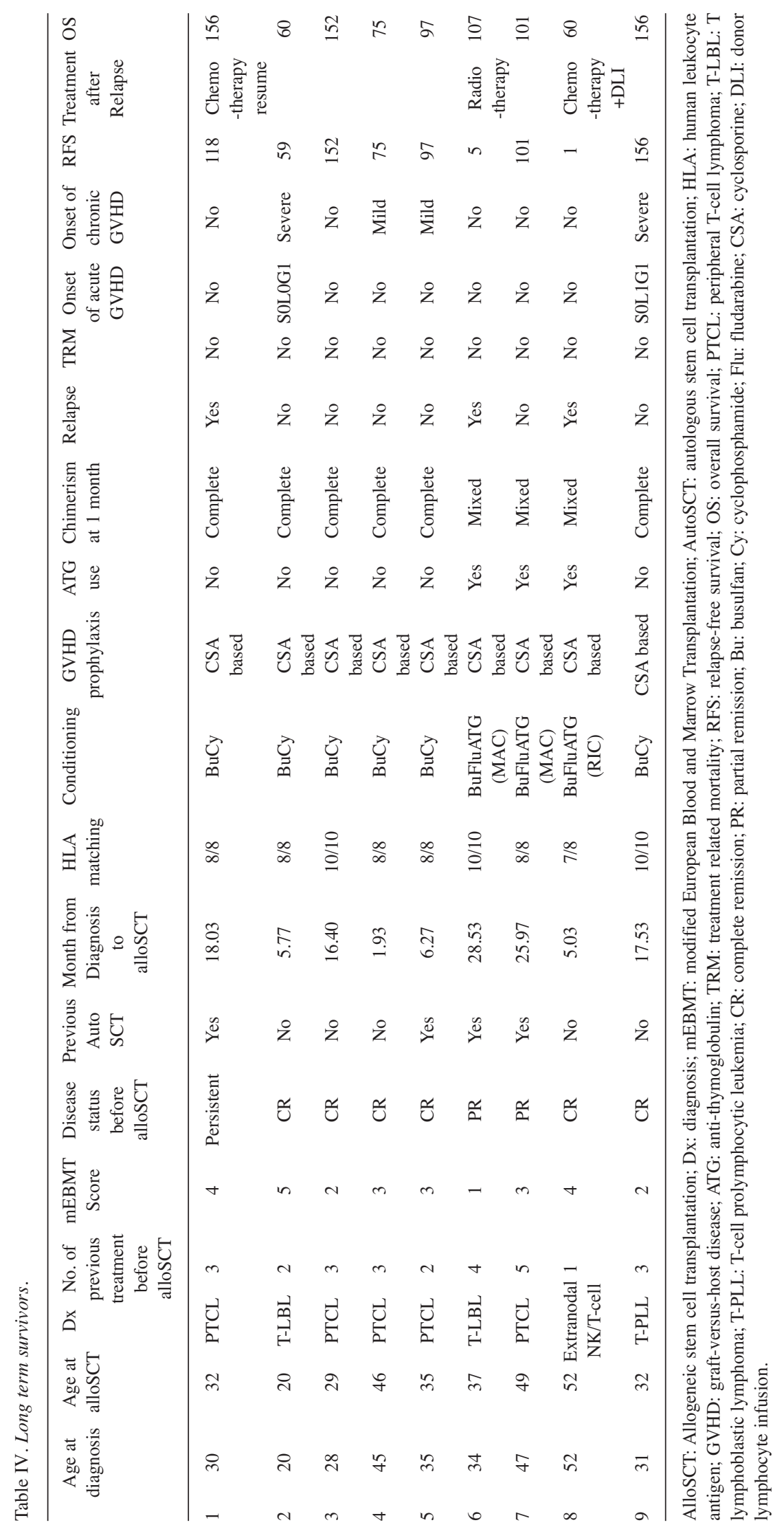


4 previous lines of treatment $(\mathrm{HR}=5.779,95 \% \mathrm{CI}=1.547$ $21.591, p<0.009)$ and $\mathrm{NK} / \mathrm{T}$ cell lymphoma subtype $(\mathrm{HR}=17.444, \quad 95 \% \mathrm{CI}=2.577-118.094, \quad p=0.003) \quad$ were associated with shorter survival, whereas $\mathrm{CR}$ status at the time of alloSCT $(\mathrm{HR}=0.090,95 \% \mathrm{CI}=0.015-0.546, p=0.009)$ was associated with longer survival.

Long-term survivors. Long-term survivors were defined as patients surviving longer than 60 months post-alloSCT, either with or without relapse. As shown in Table IV, there were 9 long-term survivors: 5 patients with PTCL, 2 with TLBL, 1 with T-PLL and 1 with extranodal NK-T cell lymphoma. The median RFS and OS for these patients were 97 months and 101 months, respectively. Eight patients $(88.9 \%)$ had full-matched donors and underwent alloSCT when their disease was under control (i.e., CR or PR state). The median number of treatments prior to alloSCT was 3 . All but 1 patients underwent MAC. Three patients (33.3\%) relapsed, and all received further treatment: 1 was treated with chemotherapy alone, 1 was treated with chemotherapy and donor lymphocyte infusion (DLI) while 1 was treated with radiotherapy alone. Further details of these patients are presented in Table V.

\section{Discussion}

We conducted this study to determine the feasibility of alloSCT in patients with mature $\mathrm{T}$ and NK cell neoplasms and found that 1) earlier implementation and good disease control at the time of alloSCT leads to better outcomes; 2) some subtypes of mature T and NK cell neoplasms may not benefit from alloSCT; and 3) alloSCT with RIC is an attractive salvage option, with similar efficacy to and less toxicity than MAC.

According to our study, alloSCT seems to be a viable treatment option for patients with mature $\mathrm{T}$ and NK cell neoplasms. In our cohort of 42 patients, the 1- and 3-year RFS rates were $55.6 \%$ and $51.3 \%$, respectively, and 1- and 3-years OS rates were $57.9 \%$ and $54.4 \%$, respectively. These results are comparable to previous studies reporting the clinical advantages of alloSCT in T-cell lymphoma treatment $(7,15-$ 17). Specifically, the reported 1-year RFS for angioimmunoblastic T-cell lymphoma (AITL) is $62 \%$ and 1 year OS 53\% (15). For PTCL and advanced mycosis fungoides/Sezary syndrome, the reported 3-year progressionfree survival was $30 \%$; $45 \%$ with predominantly nodal histologies [peripheral T-cell lymphoma (PTCL), not otherwise specified (NOS), AITL, and anaplastic large cell lymphoma (ALCL)], 6\% with predominantly extranodal histologies (7). We identified disease status and number of previous treatments as prognostic factors for both RFS and OS.

Interestingly, we found that particular lymphoma subtypes were more likely to profit from alloSCT. PTCL patients were
Table V. Details of long-term survivors.

\begin{tabular}{lc}
\hline Characteristics & $\mathrm{N}$ \\
\hline Age at alloSCT, years* (median, range) & $35.1(20-52)$ \\
Gender, male & $7(77.8 \%)$ \\
Lymphoma subtypes & $2(22.2 \%)$ \\
Peripheral T-cell lymphoma & $5(55.6 \%)$ \\
T lymphoblastic lymphoma & $1(11.1 \%)$ \\
NK/T cell lymphoma & $1(11.1 \%)$ \\
T-cell prolymphocytic leukemia & $1(11.1 \%) / 2(22.2 \%) /$ \\
Modified EBMT risk score & $3(33.3 \%) / 2(22.2 \%) / 1(11.1 \%)$ \\
1/2/3/4/5 & \\
& \\
Previous lines of treatment & $(77.8 \%) / 2(22.2 \%)$ \\
before alloSCT & $4(44.4 \%)$ \\
$<4 / \geq 4$ & $16.4(1.93-28.53)$ \\
Previous autoSCT & \\
Time from diagnosis to alloSCT, & \\
months & \\
Disease status at transplantation & $6(66.7 \%) / 2(22.2 \%) / 1(11.1 \%)$ \\
CR/PR/Others & \\
Conditioning regimen & $6(66.7 \%) / 3(33.3 \%)$ \\
MAC/RIC & $27(64.3 \%)$ \\
Donor source & $11(26.2 \%)$ \\
Matched related donor & $4(9.5 \%)$ \\
Matched unrelated donor & $2(22.2 \%)$ \\
Haplo-identical & $4.58(1.26-8.06)$ \\
Sex matching & \\
Female donor to male recipient & $(100 \%) / 0(0 \%) / 3(33.3 \%)$ \\
Infused CD34, $\times 106 / k g *$ & \\
GVHD prophylaxis & \\
Cyclosporine/Tacrolimus/ATG & $(66.7 \%) / 3(33.3 \%)$ \\
Chimerism at 1 month & \\
Complete/Mixed & \\
Onset of acute GVHD/chronic GVHD & \\
Relapse & \\
& \\
& \\
&
\end{tabular}

AlloSCT: Allogeneic stem cell transplantation; EBMT: European Blood and Marrow Transplantation; autoSCT: autologous stem cell transplantation; CR: complete remission; PR: partial remission; MAC: myeloablative conditioning; RIC: reduced intensity conditioning; CD34: cluster of differentiation 34; GVHD: graft-versus-host disease; ATG: anti-thymoglobulin. *Represents median (range)

associated with longest survival, thus these patients were subjected to further investigations (Table VI). In the PTCL group, 10 patients $(66.6 \%)$ were previously treated with autoSCT and 11 patients $(73.3 \%)$ were treated with CHOP chemotherapy (cyclophosphamide, doxorubicin, vincristine, and prednisone) as the 1st line of treatment. The OS and PFS rates were superior in patients who received previous autoSCT but the difference did not reach statistical significance (Figure $4 \mathrm{~A}, p=0.785$ and Figure $5 \mathrm{~A}, p=0.765)$. Additionally, the followings are also related to longer RFS and OS in the subgroup analysis of patients with PTCL, but not statistically significant: disease status at the time of alloSCT (Figure 4C and Figure 5C), 1st line chemotherapy, CHOP vs. Non-CHOP (Figure 4D and Figure 5D) and CR1 duration (Figure 4E and 


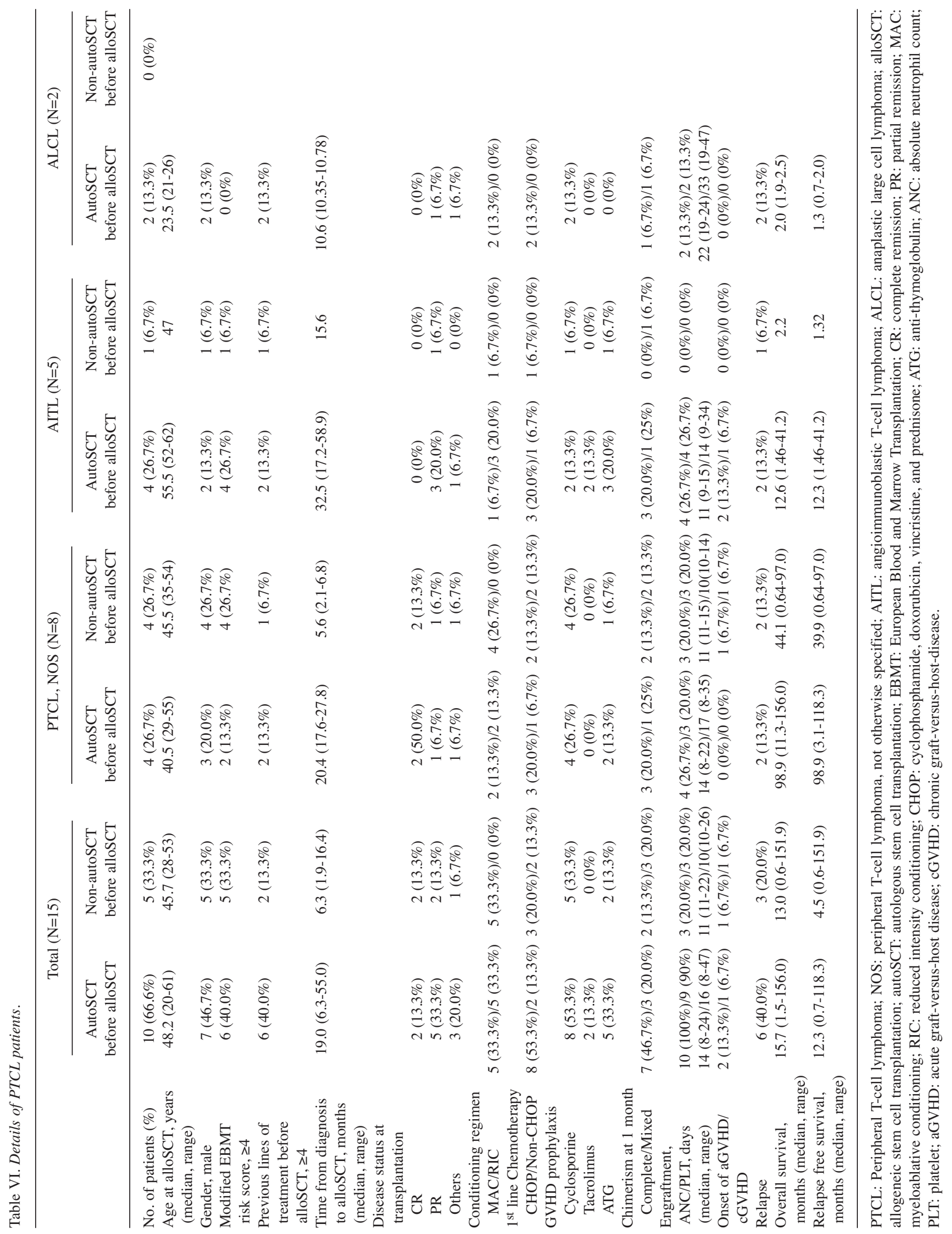


Figure 5E). Among various subtypes of PTCL, patients with PTCL, NOS showed long RFS and OS compared to other subtypes (Figure 4B, $p=0.041$ and Figure $5 \mathrm{~B}, p=0.074$ ). It is also worth noting that patients with NK/T-cell lymphoma showed significantly inferior RFS $(\mathrm{HR}=5.186,95 \% \mathrm{CI}=0.877$ $30.669, p=0.070)$ and $\mathrm{OS}(\mathrm{HR}=17.444,95 \% \mathrm{CI}=2.577$ 118.094, $p=0.003)$. The limited role of alloSCT in NK/T-cell lymphoma has been recently reported by Kim et al. (18), and our data supports their findings.

Another focus of interest was the intensity of conditioning regimen. Conditioning regimen for lymphomas has traditionally been MAC in nature, but this entails higher risk of TRM and GVHD (16). In recent years, alloSCT with RIC has gained popularity based on acceptable RFS and OS, but the major pitfall is the higher relapse rates $(4,19-21)$. In our cohort, there were no differences in survival and GVHD incidence according to conditioning intensity, but RIC showed lower 1-year TRM rates (RIC, $10.5 \%$ vs. MAC, 26.1\%). Since many patients undergoing alloSCT are associated with physical debilitation from extensive chemotherapy, RIC can be a good option even for younger patients.

Lastly, there were 4 patients undergoing haplo-identical stem cell transplantation (haplo-SCT) in our cohort (Table VII). Neutrophil and platelet engraftment were observed in all 4 patients and the median RFS was 11 months. None of them experienced TRM. In general, approximately $30 \%$ of patients have matched sibling donors. Additional 40-50\% of patients have matched unrelated donors (MUDs), but 20$30 \%$ of the patients require an alternative donor. In particular, in the treatment setting of lymphoma where 'planned' alloSCT is often not possible, there is a higher chance that the immediately available donor is not a matched one. Recently, the Center for International Blood and Marrow Transplant Research reported that the outcomes of haplo-SCT in patients with non-Hodgkin's lymphoma were comparable to those achieved with alloSCT from MUD (22, 23). Specifically, haplo-SCT showed a similar 3-year TRM (15\% vs. 13\%), 2-year incidence of relapse (37\% vs. 40\%), 3 -year PFS (48\% vs. 48\%), 2-year OS (61\% vs. 62\%) and 100 -day incidence of grade II-IV acute GVHD (27\% vs. $25 \%$ ) compared to alloSCT from MUD. Although very few patients underwent haplo-SCT in our cohort, our results also support the previous studies about feasibility of haploalloSCT in the setting of non-Hodgkin's lymphoma (24).

One of the most obvious pitfalls of this study is its retrospective nature. As such, there may be selection bias for patients who underwent alloSCT. In addition, although 42 patients with mature $\mathrm{T}$ and $\mathrm{NK}$ cell neoplasms undergoing alloSCT is not a small number considering the rarity of the disease, there are perhaps too few patients to draw statistically powerful conclusions. Thus, our results should be cautiously interpreted and confirmed by further studies with a larger number of patients.

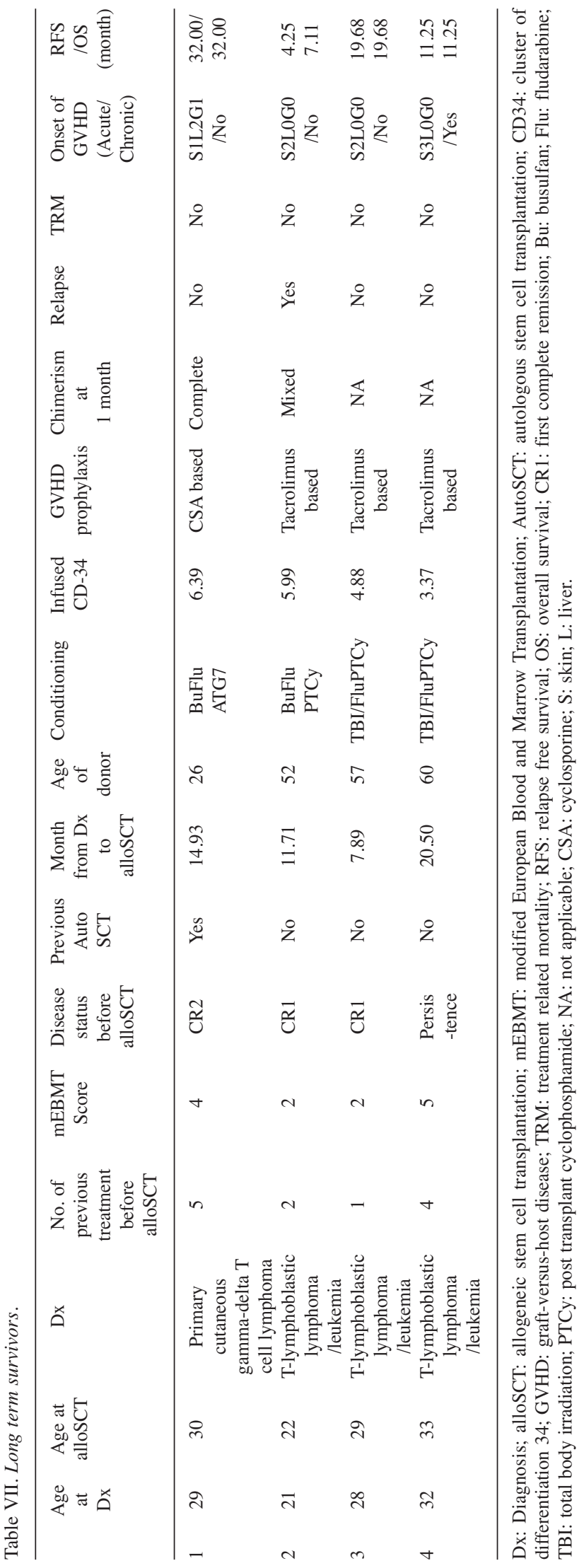




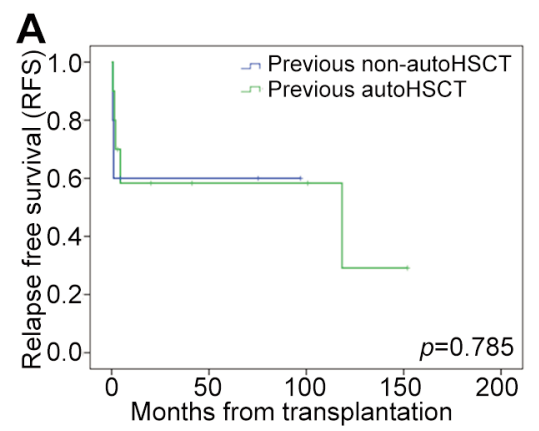

D
B

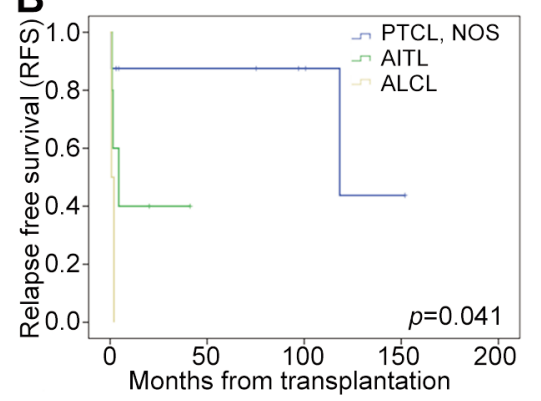

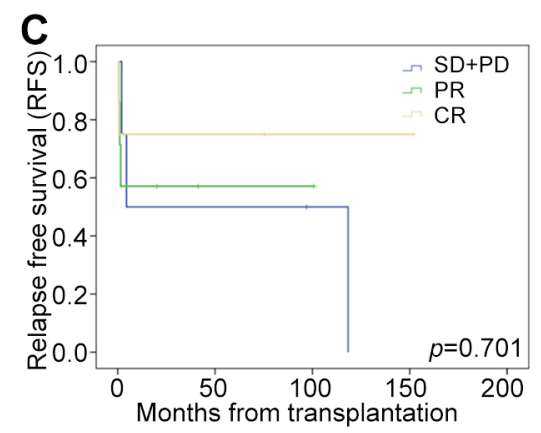

E

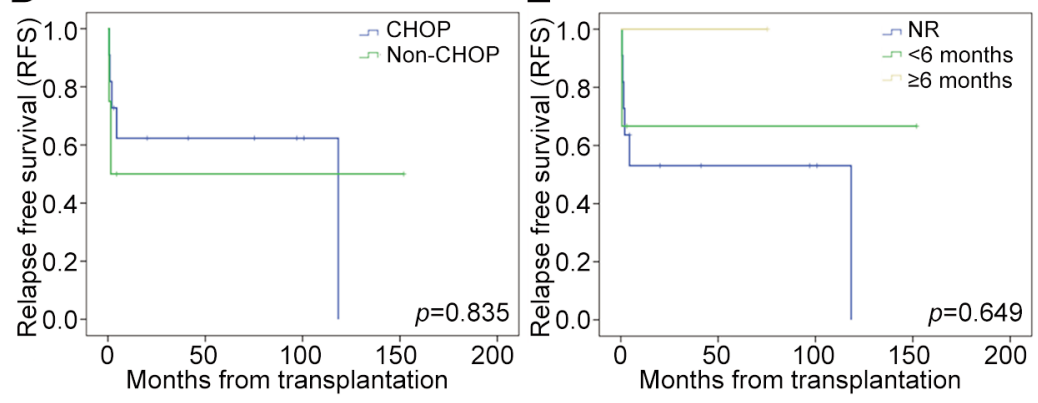

Figure 4. Kaplan-Meier curves of relapse-free survival of PTCL patients. (A) History of previous autoSCT; (B) subtype of PTCL; (C) disease status at alloSCT; (D) 1st line chemotherapy including cyclophosphamide, doxorubicin, vincristine, and prednisone (CHOP) vs. Non-CHOP; (E) CR1 duration, <6 vs. $\geq 6$ months. PTCL: Peripheral T-cell lymphoma; AITL: angioimmunoblastic T-cell lymphoma; ALCL: anaplastic large cell lymphoma; CR: complete response; PR: partial response; autoSCT: autologous stem cell transplantation; alloSCT: allogenic stem cell transplantation; NOS: not otherwise specified.
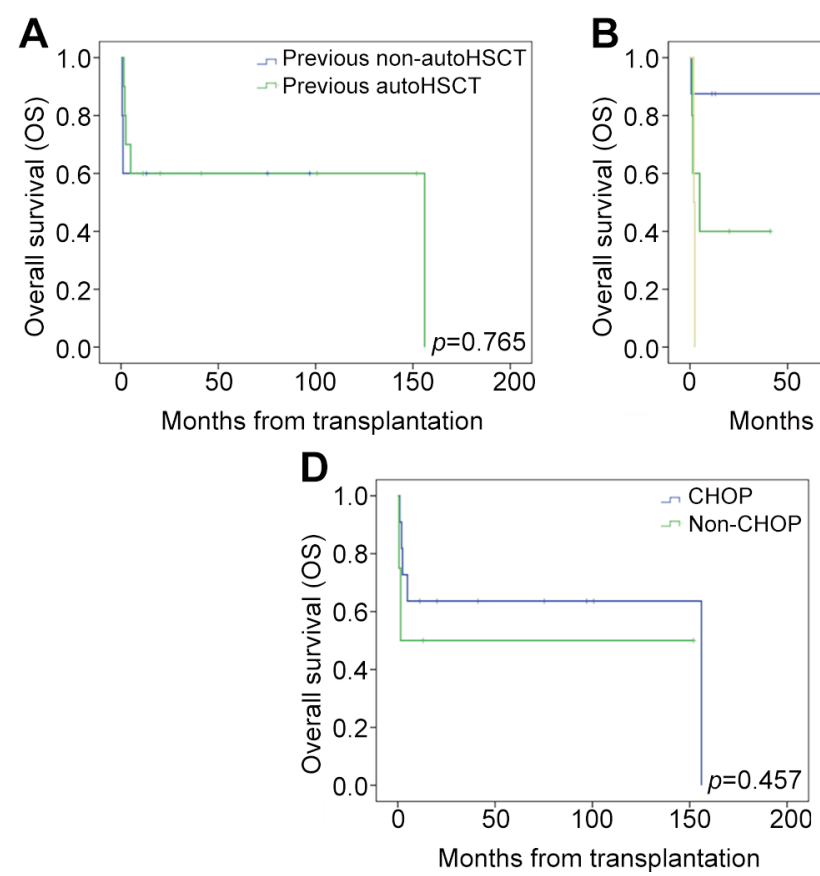
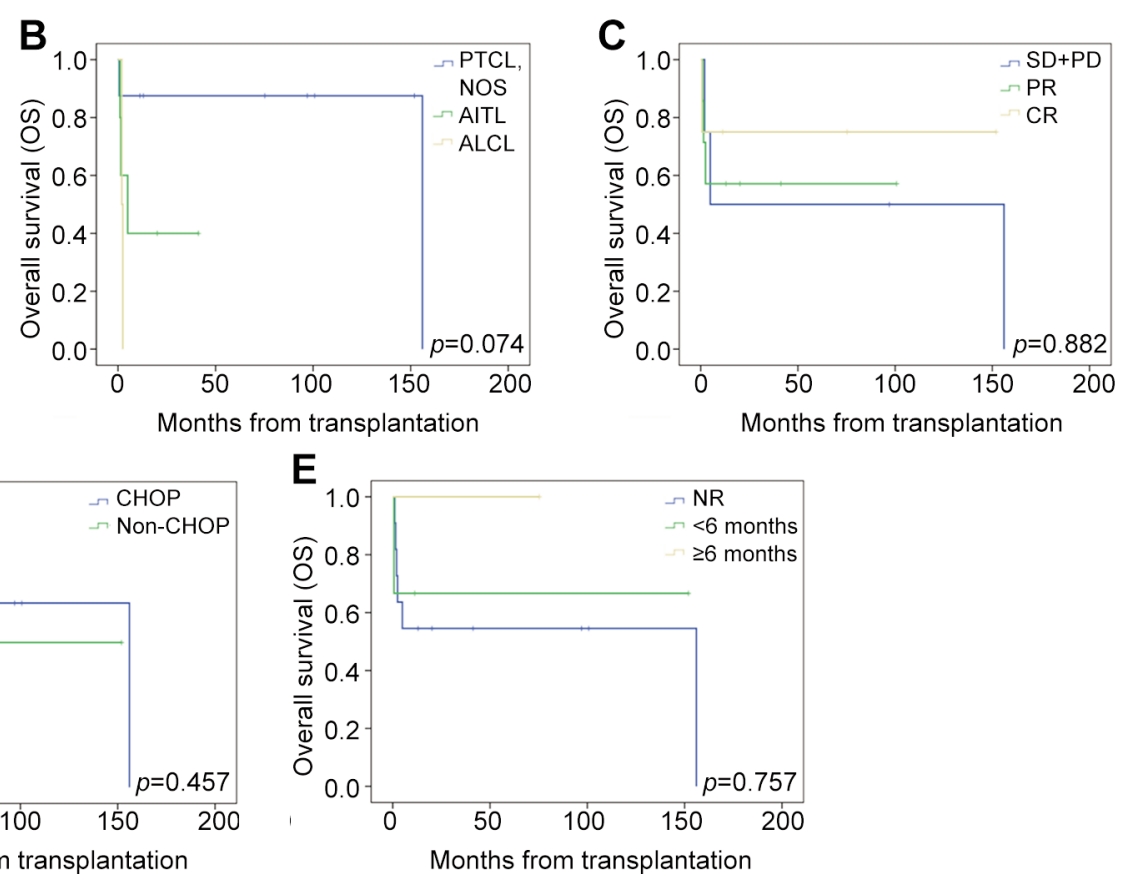

Figure 5. Kaplan-Meier curves of overall survival of PTCL patients. (A) History of previous autoSCT; (B) subtype of PTCL; (C) disease status at alloSCT; (D) 1st line chemotherapy including cyclophosphamide, doxorubicin, vincristine, and prednisone (CHOP) vs. Non-CHOP; (E) CR1 duration, $<6$ vs. $\geq 6$ months. PTCL: Peripheral T-cell lymphoma; autoSCT: autologous stem cell transplantation; alloSCT: allogenic stem cell transplantation; AITL: angioimmunoblastic T-cell lymphoma; ALCL: anaplastic large cell lymphoma; CR: complete response; PR: partial response; SD: stable disease; PD: progressive disease; NOS: not otherwise specified. 
In conclusion, alloSCT represents a viable treatment option in patients with certain subtypes of mature T and NK cell neoplasms, given that some patients experience a long durable remission. Our results suggest that if alloSCT is considered, the outcomes are best when this treatment is used earlier and when disease is well controlled prior to transplant. Finally, the use of RIC can mitigate the toxicity concerns traditionally associated with alloSCT in patients with lymphoma without compromising the outcomes.

\section{Conflicts of Interest}

The Authors have no conflicts of interest to disclose in relation to this study.

\section{Authors' Contributions}

Conceptualization, JMB; methodology, formal analysis, EHJ and JMB; investigation, data curation, all authors; supervision, JMB; writing-original draft preparation, EHJ and JMB; writing-review and editing, all Authors.

\section{Acknowledgements}

The results of this study have been submitted to the International Congress of Bone Marrow Transplantation 2020, Korea.

\section{References}

1 Swerdlow SH, Campo E, Pileri SA, Harris NL, Stein H, Siebert R, Advani R, Ghielmini M, Salles GA, Zelenetz AD and Jaffe ES: The 2016 revision of the World Health Organization classification of lymphoid neoplasms. Blood 127(20): 23752390, 2016. PMID: 26980727. DOI: 10.1182/blood-2016-01643569

2 Schetelig J, Fetscher S, Reichle A, Berdel WE, Beguin Y, Brunet S, Caballero D, Majolino I, Hagberg H, Johnsen HE, Kimby E, Montserrat E, Stewart D, Copplestone A, Rösler W, Pavel J, Kingreen D and Siegert W: Long-term disease-free survival in patients with angioimmunoblastic T-cell lymphoma after highdose chemotherapy and autologous stem cell transplantation. Haematologica 88(11): 1272-1278, 2003. PMID: 14607756.

3 Kyriakou C, Canals C, Goldstone A, Caballero D, Metzner B, Kobbe G, Kolb HJ, Kienast J, Reimer P, Finke J, Oberg G, Hunter A, Theorin N, Sureda A, Schmitz N and OutcomeLymphoma Working Party of the European Group for Blood and Marrow Transplantation: High-dose therapy and autologous stem-cell transplantation in angioimmunoblastic lymphoma: complete remission at transplantation is the major determinant of Outcome-Lymphoma Working Party of the European Group for Blood and Marrow Transplantation. J Clin Oncol 26(2): 218224, 2008. PMID: 18182664. DOI: 10.1200/JCO.2008.12.6219

4 Corradini P, Dodero A, Zallio F, Caracciolo D, Casini M, Bregni M, Narni F, Patriarca F, Boccadoro M, Benedetti F, Rambaldi A, Gianni AM and Tarella C: Graft-versus-lymphoma effect in relapsed peripheral T-cell non-Hodgkin's lymphomas after reduced-intensity conditioning followed by allogeneic transplantation of hematopoietic cells. J Clin Oncol 22(11): 2172-2176, 2004. PMID: 15169805. DOI: 10.1200/JCO. 2004.12.050

5 Dodero A, Spina F, Narni F, Patriarca F, Cavattoni I, Benedetti F, Ciceri F, Baronciani D, Scimè R, Pogliani E, Rambaldi A, Bonifazi F, Dalto S, Bruno B and Corradini P: Allogeneic transplantation following a reduced-intensity conditioning regimen in relapsed/refractory peripheral T-cell lymphomas: long-term remissions and response to donor lymphocyte infusions support the role of a graft-versus-lymphoma effect. Leukemia 26(3): 520-526, 2012. PMID: 21904377. DOI: 10.1038/leu.2011.240

6 Smith SM, Burns LJ, van Besien K, Lerademacher J, He W, Fenske TS, Suzuki R, Hsu JW, Schouten HC, Hale GA, Holmberg LA, Sureda A, Freytes CO, Maziarz RT, Inwards DJ, Gale RP, Gross TG, Cairo MS, Costa LJ, Lazarus HM, Wiernik PH, Maharaj D, Laport GG, Montoto S and Hari PN: Hematopoietic cell transplantation for systemic mature T-cell non-Hodgkin lymphoma. J Clin Oncol 31(25): 3100-3109, 2013. PMID: 23897963. DOI: 10.1200/JCO.2012.46.0188

7 Jacobsen ED, Kim HT, Ho VT, Cutler CS, Koreth J, Fisher DC, Armand P, Alyea EP, Freedman AS, Soiffer RJ and Antin JH: A large single-center experience with allogeneic stem-cell transplantation for peripheral T-cell non-Hodgkin lymphoma and advanced mycosis fungoides/Sezary syndrome. Ann Oncol 22(7): 1608-1613, 2011. PMID: 21252059. DOI: 10.1093/ annonc/mdq698

8 Jaffe ES, Harris NL, Diebold J and Muller-Hermelink HK: World Health Organization classification of neoplastic diseases of the hematopoietic and lymphoid tissues. A progress report. Am J Clin Pathol 111(1 Suppl 1): S8-12, 1999. PMID: 9894466.

9 Campo E, Swerdlow SH, Harris NL, Pileri S, Stein H and Jaffe ES: The 2008 WHO classification of lymphoid neoplasms and beyond: evolving concepts and practical applications. Blood 117(19): 5019-5032, 2011. PMID: 21300984. DOI: 10.1182/ blood-2011-01-293050

10 Cheson BD, Pfistner B, Juweid ME, Gascoyne RD, Specht L, Horning SJ, Coiffier B, Fisher RI, Hagenbeek A, Zucca E, Rosen ST, Stroobants S, Lister TA, Hoppe RT, Dreyling M, Tobinai K, Vose JM, Connors JM, Federico M, Diehl V and International Harmonization Project on Lymphoma: Revised response criteria for malignant lymphoma. J Clin Oncol 25(5): 579-586, 2007. PMID: 17242396. DOI: 10.1200/JCO.2006.09.2403

11 Cheson BD, Fisher RI, Barrington SF, Cavalli F, Schwartz LH, Zucca E, Lister TA, Alliance, Australasian Leukaemia and Lymphoma Group, Eastern Cooperative Oncology Group, European Mantle Cell Lymphoma Consortium, Italian Lymphoma Foundation, European Organisation for Research, Treatment of Cancer/Dutch Hemato-Oncology Group, Grupo Español de Médula Ósea, German High-Grade Lymphoma Study Group, German Hodgkin's Study Group, Japanese Lymphorra Study Group, Lymphoma Study Association, NCIC Clinical Trials Group, Nordic Lymphoma Study Group, Southwest Oncology Group and United Kingdom National Cancer Research Institute: Recommendations for initial evaluation, staging, and response assessment of Hodgkin and non-Hodgkin lymphoma: the Lugano classification. J Clin Oncol 32(27): 3059-3068, 2014. PMID: 25113753. DOI: 10.1200/JCO.2013.54.8800

12 Bacigalupo A, Ballen K, Rizzo D, Giralt S, Lazarus H, Ho V, Apperley J, Slavin S, Pasquini M, Sandmaier BM, Barrett J, 
Blaise D, Lowski R and Horowitz M: Defining the intensity of conditioning regimens: working definitions. Biol Blood Marrow Transplant 15(12): 1628-1633, 2009. PMID: 19896087. DOI: 10.1016/j.bbmt.2009.07.004

13 Glucksberg H, Storb R, Fefer A, Buckner CD, Neiman PE, Clift RA, Lerner KG and Thomas ED: Clinical manifestations of graft-versus-host disease in human recipients of marrow from HL-A-matched sibling donors. Transplantation 18(4): 295-304, 1974. PMID: 4153799. DOI: 10.1097/00007890-19741000000001

14 Jagasia MH, Greinix HT, Arora M, Williams KM, Wolff D, Cowen EW, Palmer J, Weisdorf D, Treister NS, Cheng GS, Kerr H, Stratton P, Duarte RF, McDonald GB, Inamoto Y, Vigorito A, Arai S, Datiles MB, Jacobsohn D, Heller T, Kitko CL, Mitchell SA, Martin PJ, Shulman H, Wu RS, Cutler CS, Vogelsang GB, Lee SJ, Pavletic SZ and Flowers ME: National Institutes of Health Consensus development project on criteria for clinical trials in chronic graft-versus-host disease: I. The 2014 Diagnosis and Staging Working Group report. Biol Blood Marrow Transplant 21(3): 389-401.e1, 2015. PMID: 25529383. DOI: 10.1016/j.bbmt.2014.12.001

15 Kyriakou C, Canals C, Finke J, Kobbe G, Harousseau JL, Kolb HJ, Novitzky N, Goldstone AH, Sureda A and Schmitz N: Allogeneic stem cell transplantation is able to induce long-term remissions in angioimmunoblastic T-cell lymphoma: a retrospective study from the lymphoma working party of the European group for blood and marrow transplantation. J Clin Oncol 27(24): 3951-3958, 2009. PMID: 19620487. DOI: 10.1200/JCO.2008.20.4628

16 van Besien K, Loberiza FR Jr, Bajorunaite R, Armitage JO, Bashey A, Burns LJ, Freytes CO, Gibson J, Horowitz MM, Inwards DJ, Marks DI, Martino R, Maziarz RT, Molina A, Pavlovsky S, Pecora AL, Schouten HC, Shea TC, Lazarus HM, Rizzo JD and Vose JM: Comparison of autologous and allogeneic hematopoietic stem cell transplantation for follicular lymphoma. Blood 102(10): 3521-3529, 2003. PMID: 12893748. DOI: 10.1182/blood-2003-04-1205

17 Mussetti A, Martinetti N, Cieri N, Pennisi M, Dodero A and Corradini P: Real-life feasibility of salvage allogeneic transplantation in peripheral T-cell lymphomas. Bone Marrow Transplant 54(8): 1237-1244, 2019. PMID: 30531956. DOI: 10.1038/s41409-018-0417-9

18 Jeong SH, Song HN, Park JS, Yang DH, Koh Y, Yoon SS, Lee HW, Eom HS, Won JH, Kim WS and Kim SJ: Allogeneic stem cell transplantation for patients with natural killer/T cell lymphoid malignancy: A multicenter analysis comparing upfront and salvage transplantation. Biol Blood Marrow Transplant 24(12): 2471-2478, 2018. PMID: 30064012. DOI: 10.1016/ j.bbmt.2018.07.034

19 Ishida T, Hishizawa M, Kato K, Tanosaki R, Fukuda T, Taniguchi S, Eto T, Takatsuka Y, Miyazaki Y, Moriuchi Y, Hidaka M, Akashi K, Uike N, Sakamaki H, Morishima Y, Kato $\mathrm{K}$, Suzuki R, Nishiyama T and Utsunomiya A: Allogeneic hematopoietic stem cell transplantation for adult T-cell leukemialymphoma with special emphasis on preconditioning regimen: a nationwide retrospective study. Blood 120(8): 1734-1741, 2012. PMID: 22689862. DOI: 10.1182/blood-2012-03-414490
20 Kharfan-Dabaja MA, El-Jurdi N, Ayala E, Kanate AS, Savani $\mathrm{BN}$ and Hamadani M: Is myeloablative dose intensity necessary in allogeneic hematopoietic cell transplantation for lymphomas? Bone Marrow Transplant 52(11): 1487-1494, 2017. PMID: 28368373. DOI: $10.1038 / \mathrm{bmt} .2017 .55$

21 Mamez AC, Dupont A, Blaise D, Chevallier P, Forcade E, Ceballos P, Mohty M, Suarez F, Beguin Y, Peffault De Latour R, Rubio MT, Tournilhac O and Nguyen S: Allogeneic stem cell transplantation for peripheral $\mathrm{T}$ cell lymphomas: a retrospective study in 285 patients from the Société Francophone de Greffe de Moelle et de Thérapie Cellulaire (SFGM-TC). J Hematol Oncol 13(1): 56, 2020. PMID: 32429979. DOI: 10.1186/s13045020-00892-4

22 Kanate AS, Mussetti A, Kharfan-Dabaja MA, Ahn KW, DiGilio A, Beitinjaneh A, Chhabra S, Fenske TS, Freytes C, Gale RP, Ganguly S, Hertzberg M, Klyuchnikov E, Lazarus HM, Olsson R, Perales MA, Rezvani A, Riches M, Saad A, Slavin S, Smith SM, Sureda A, Yared J, Ciurea S, Armand P, Salit R, BolañosMeade J and Hamadani M: Reduced-intensity transplantation for lymphomas using haploidentical related donors vs. HLAmatched unrelated donors. Blood 127(7): 938-947, 2016. PMID: 26670632. DOI: 10.1182/blood-2015-09-671834

23 Ghosh N, Karmali R, Rocha V, Ahn KW, DiGilio A, Hari PN, Bachanova V, Bacher U, Dahi P, de Lima M, D'Souza A, Fenske TS, Ganguly S, Kharfan-Dabaja MA, Prestidge TD, Savani BN, Smith SM, Sureda AM, Waller EK, Jaglowski S, Herrera AF, Armand P, Salit RB, Wagner-Johnston ND, Fuchs E, BolañosMeade $\mathrm{J}$ and Hamadani M: Reduced-intensity transplantation for lymphomas using haploidentical related donors versus HLAmatched sibling donors: A center for International Blood and Marrow Transplant Research analysis. J Clin Oncol 34(26): 3141-3149, 2016. PMID: 27269951. DOI: 10.1200/JCO. 2015.66.3476

24 Ma L, Han X, Jiang S, Meng Q, Zhang L and Bao H: Haploidentical stem cell transplantation $v s$. matched unrelated donor transplantation in adults with hematologic malignancies: a systematic review and meta-analysis. Hematology 25(1): 356365, 2020. PMID: 33054609. DOI: 10.1080/16078454. 2020.1831292
Received March 23, 2021

Revised May 14, 2021

Accepted May 24, 2021 